\title{
ADENOTONSILLECTOMY: DAY-CASE PROCEDURE
}

\author{
ME Baraka, Consultant ENT Surgeon \\ Royal Lancaster Infirmary
}

\section{INTRODUCTION}

The use of ambulatory surgery for adenotonsillectomy is becoming a well-established procedure. An audit analysis of this procedure, on the basis of no overnight hospital stay, is reported from the ENT department at the Royal Lancaster Infirmary (RLI). Patients, who had their surgery performed and were discharged from the hospital on the same day, had no more complications than those who were hospitalised for 24 hours post-operatively. Reactionary haemorrhage was not recorded in any of the 30 patients involved. Three patients (10\%) needed provision for overnight hospital stay after the operation, because of nausea and vomiting in one patient, severe dysphagia in another, and the insistence of the third patient to stay in as he liked the food and the play facilities on the ward.

Suggestions are made for patient selection and the determining factors for safe day-case adenotonsillectomy.

\section{MATERIALS AND METHODS}

The current policy adopted by the ENT department is to keep adenotonsillectomised patients in hospital for a minimum of 24 hours post-operatively. The main objective of this short audit analysis was to look into the rate and the nature of complications resulting from adenotonsillectomy in children without overnight hospital stay. The following features were analysed:

1 The incidence of reactionary haemorrhage. Reactionary haemorrhage was defined as a bleed of sufficient severity to warrant return to the operating room.

2 Any other causes that prevented same day discharge.

In the twelve-month period between February 1998 and January 1999 a total of 30 patients were listed for adenotonsillectomy, operation and discharge on the same day. The patients' parents were informed that the child should fast from midnight, and be brought to hospital two hours before the operation for the necessary pre-medications. After surgery, and before leaving hospital, parents were handed the usual instructions that are given to all adenotonsillectomised patients.

\section{RESULTS}

No serious complications were encountered. No reactionary haemorrhage was reported in any of the 30 patients who were scheduled for adenotonsillectomy as a day-case procedure. Three children, however, were detained overnight as one had severe dysphagia, the second had nausea and vomiting and the third because he liked the ward and insisted on staying in till the following day. Hence ten percent needed provision for overnight observation before discharge the following day. Twenty-seven patients (90\%) were discharged eight hours after the operation, without any problems.

\section{DISCUSSION}

In 1985, in its guidelines for day-case surgery, the Royal College of Surgeons of England excluded the removal of tonsils and adenoids for fear of reactionary haemorrhage ${ }^{(1)}$. Concern over the rising cost of healthcare, however, resulted in a number of centres moving to a 'same day' discharge policy $^{(2)}$. This has been the main reason why many of North American hospitals perform adenotonsillectomy as a day-case procedure ${ }^{(3,4)}$.

Healthcare institutions have two major objectives ${ }^{(5)}$ :

- to provide care of the highest possible quality

- to provide that care at the lowest possible cost.

In order to investigate these objectives at the RLI, this audit analysis was conducted in 30 children undergoing adenotonsillectomy on a no overnight hospital stay basis. It resulted in only ten percent of them requiring overnight stay in hospital.

The criteria for patient selection and the guidelines for performing the operation without overnight hospital stay are as follows:

\section{patient selection}

- live within easy reach of the hospital

- have available means of transportation

- have telephone

\section{hospital facilities}

- high quality nursing staff committed to providing excellent service on a day-case ward

- facilities to detain children overnight if necessary

\section{operative and postoperative precautions}

- the operation is to be carried out in a morning list

- meticulous attention to haemostasis

- close monitoring in the immediate postoperative period

- patients are not to be discharged before the lapse of at least eight hours postoperatively, as reactionary haemorrhage is known to occur in the first eight hours postadenotonsillectomy 
- severe dysphagia, pyrexia and blood clots in the tonsillar fossae (as found in a similar study carried out by the author in 1994) ${ }^{(8)}$ preclude same-day discharge

- follow-up telephone calls in the morning to the parents from the ward sister or SHO.

The safety of the patients is crucial. Historically, there has been a mortality rate of 1:2000 in adenotonsillectomy ${ }^{(9)}$ and we would not want the introduction of a new system to damage the current greatly improved rate. Units that follow the above criteria, and can closely monitor their patients and audit their results, are encouraged to consider the possibility of performing adenotonsillectomy as a day-case procedure. There will undoubtedly be great financial savings and a reduction in both patients' and parents' anxiety.

\section{CONCLUSION}

High quality care ought to be maintained, at the lowest possible cost, without jeopardising patient safety. Adenotonsillectomy is one of the most commonly performed surgical procedures in children. This audit analysis showed that it could safely be performed as a day-case procedure, provided that certain measures are observed.

\section{REFERENCES}

1 Royal College of Surgeons of England. Commission on the provision of surgical services: guidelines for day-case surgery 1985
2 Yardley MPJ Tonsillectomy, adenoidectomy and adenotonsillectomy: are they safe day case procedures? J Laryngol \& Otol 1992;106:299-300

3 Maniglia AJ, Kushner H, Cozzi L Adenotonsillectomy: a safe outpatient procedure Arch Otolaryngol, Head \& Neck Surg 1989;115:92-94

4 Shott SR, Myer III CM, Cotton RT Efficacy of tonsillectomy and adenoidectomy as an outpatient procedure: a preliminary report Int $\mathbf{J}$ Paed Otorhinolaryngol 1987; 13:157-163

5 Donabedian A Institutional and professional responsibilities in quality assurance Qual Ass in Health Care 1989;1:3-11

6 Guida RA, Mattucci KF Tonsillectomy and adenoidectomy: an inpatient or outpatient procedure? Laryngoscope 1990; 100:491-493

7 Carithers JS, Gebhart DE, Williams JA Postoperative risks of paediatric tonsilloadenoidectomy Laryngoscope 1987;97:422-429

8 Baraka ME, Telmessani LM Audit analysis in adenotonsillectomy overnight hospital stay Bahrain Medical Bulletin 1994;16:54-55

9 Rosenfeld RM, Green RP Tonsillectomy and adenoidectomy: changing trends Ann Otol, Rhinol \& Laryngol 1990;99:187-191 